\title{
The Dehalogenase Complement of a Soil Pseudomonad Grown in Closed and Open Cultures on Haloalkanoic Acids
}

\author{
By DAVID J. HARDMAN AND J. HOWARD SLATER* \\ Department of Environmental Sciences, University of Warwick, Coventry CV4 7AL, U.K.
}

(Received 5 May 1981)

\begin{abstract}
Pseudomonas sp. strain E4 was grown in continuous-flow culture with either monochloroacetate (MCA) or 2-monochloropropionate (2MCPA) as the growth-limiting substrate. In contrast to previous observations made for this organism grown in closed culture on 2MCPA, a third dehalogenase was detected under certain growth conditions, as well as dehalogenases I and II. The response of Pseudomonas sp. strain E4, in terms of its enzyme complement, varied depending on the organism's growth rate and the nature of the growth-limiting substrate. With MCA as the growth-limiting substrate, dehalogenases II and III were only detected in slowly growing organisms. With 2MCPA as growth-limiting substrate, the responses were more variable and complex. The overall dehalogenase activities also depended on the growth rate and substrate limitation, with higher dehalogenation rates found in organisms growing slowly with MCA limitation compared with 2MCPA limitation. In fast growing organisms the relative rates of dehalogenation were reversed for the two limitations.
\end{abstract}

\section{INTRODUCTION}

Possession of enzymes known as dehalogenases (Jensen, 1960; Slater et al., 1979) or halidohydrolases (Goldman et al., 1968; Little \&Williams, 1971) enables micro-organisms to utilize halogenated alkanoic acids as their sole carbon and energy sources. Several bacteria have been isolated from soil with different dehalogenating capabilities towards monochloroacetic acid (MCA), dichloroacetic acid (DCA), 2-monochloropropionic acid (2MCPA) and 2,2-dichloropropionic acid (22DCPA) (Hardman \& Slater, 1981). Subsequent analysis of the bacteria identified four dehalogenases on the basis of their relative mobilities during discontinuous gel electrophoresis. These were termed dehalogenases I, II, III and IV. The isolates were characterized by the presence of different combinations of the four dehalogenases (Hardman \& Slater, 1981).

In the initial study no attempt was made to examine systematically either the effect of different halogenated alkanoic acids as enzyme inducers or the effect of different growth conditions or growth rates on the expression of dehalogenase enzymes and their specific activities. It was apparent that either MCA or 2MCPA induced all those enzymes expressed during closed culture growth and present in late-exponential phase cultures (Hardman \& Slater, 1981). We have suggested that the dehalogenase system provides a good system for examining the evolution of catalytic activities (Bull et al., 1976; Weightman \& Slater, 1980). In addition, particularly in those strains containing two or more dehalogenases, it is possible that these organisms will provide an opportunity to study the pattern of complex regulatory mechanisms, their interaction and, perhaps, the evolution of control mechanisms. Previous studies (Slater et al., 1979; Weightman \& Slater, 1980) have shown that the organism's growth rate significantly affects dehalogenase specific activities, with a pattern characteristic of catabolic enzymes (Clarke \& Lilly, 1969; Dean, 1972). 
This paper describes the influence of growth rate and growth-limiting substrate on the dehalogenase activity of Pseudomonas sp. strain E4. The organism was grown in chemostat culture with either MCA or 2MCPA as growth-limiting substrate.

\section{METHODS}

Abbreviations. MCA, monochloroacetic acid; DCA, dichloroacetic acid; 2MCPA, 2-monochloropropionic acid: 22DCPA, 2,2-dichloropropionic acid.

Maintenance and growth of the bacterium. Pseudomonas sp. strain E4, a member of the non-fluorescent group, previously designated isolate E4 by Hardman \& Slater (1981) and identified by the National Collection of Industrial Bacteria, Torry Research Station, was isolated from soil samples after closed culture enrichment with 2MCPA as the carbon and energy source and maintained as previously described (Slater et al., 1979).

The chemostat continuous-flow cultures were grown in glass vessels. The culture volume was $1000 \mathrm{ml}$, agitated

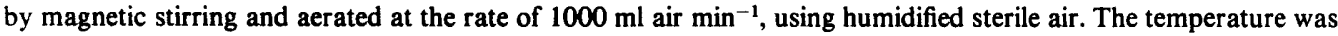
maintained at $30^{\circ} \mathrm{C}$ using a Churchill heating unit (Churchill Instruments, Uxbridge, Middx.), and fresh medium was transferred into the growth vessel using flow inducers (Watson-Marlow, Falmouth, Cornwall). The closed culture growth medium described by Hardman \& Slater (1981) was used supplemented with $15 \mathrm{mg}$ yeast extract $1^{-1}$.

Measurement of dehalogenase activity. Dehalogenase activity in cell-free extracts was measured as previously described (Weightman \& Slater, 1980; Hardman \& Slater, 1981). The principle of the enzyme assay involves measuring free chloride ions, released during the assay period, with a Marius Chlor-o-Counter (Labo International, Holland). Protein concentration was estimated by the biuret method (Gornall et al., 1949) using bovine serum albumin as the reference protein. Specific activities are expressed as $\mu \mathrm{mol}$ substrate converted $(\mathrm{mg}$ protein $)^{-1} \min ^{-1}$.

Polyacrylamide gel electrophoresis. The different dehalogenases were separated by discontinuous polyacrylamide gel electrophoresis of cell-free extracts as previously described (Weightman \& Slater, 1980; Hardman \& Slater, 1981). The gels were loaded with $50 \mu \mathrm{l}$ with a total protein content ranging from 5 to $20 \mu \mathrm{g}$ protein $\mathrm{ml}^{-1}$. The position of dehalogenases in the gel was detected by first incubating the gels for approximately $20 \mathrm{~min}$ in the presence of chlorinated substrates (MCA and DCA each at a concentration of $50 \mathrm{~mm}$ ) followed by a second incubation in a solution of silver nitrate. This resulted in the precipitation of silver chloride at the site of enzyme activity (chloride ion release) for the chlorinated alkanoic acids.

Materials. All materials were of the highest commercially available purity as described previously (Slater et al., 1979; Weightman \& Slater, 1980).

\section{RESULTS}

The enzyme analyses and gel separations previously reported showed that in lateexponential phase closed cultures of Pseudomonas sp. strain E4, dehalogenase I with activity towards MCA, DCA, 2MCPA and 22DCPA was the principal enzyme, but with some MCA dehalogenation associated with low levels of dehalogenase II (Hardman \& Slater, 1981). The substrate activity ratios $(1: 2 \cdot 11: 0 \cdot 26: 0 \cdot 11$ for MCA :DCA :2MCPA :22DCPA, respectively) were constant suggesting that dehalogenation depended mainly on the activity of a single dehalogenase. The original aim of the present experiments was to determine whether or not there were any growth conditions under which dehalogenase II activity assumed more significance. Accordingly, the organism was grown in two different chemostats with either MCA or 2MCPA as the growth-limiting substrate in order to examine the effect of the specific growth rate and growth-limiting substrate on the specific activities of the enzymes and their possible interaction. Chemostat growth on MCA was believed possible since dehalogenase II exhibited activity only towards MCA and, in view of the fact that Pseudomonas sp. strain E4 was isolated and usually grown with 2MCPA as the carbon source, it was considered possible that under conditions of growth on MCA this enzyme might assume greater importance. Conversely, growth on 2MCPA in chemostat culture might have been expected to emphasize the importance of dehalogenase I with its 2MCPA dehalogenation capability. 
Table 1. Effect of dilution rate on the dehalogenase specific activities in steady-state cultures of Pseudomonas sp. strain E4 grown with MCA as the growth-limiting substrate

The dehalogenase assays were repeated three to five times using different samples taken from the chemostat at a given dilution rate.

\begin{tabular}{|c|c|c|c|c|c|c|}
\hline \multirow{2}{*}{$\begin{array}{l}\text { Length of } \\
\text { steady state } \\
\text { (h) }\end{array}$} & \multirow{2}{*}{$\begin{array}{l}\text { Dilution rate } \\
\qquad\left(h^{-1}\right)\end{array}$} & \multirow{2}{*}{$\begin{array}{l}\% \text { of } \\
\mu_{\max }\end{array}$} & \multicolumn{4}{|c|}{$\begin{array}{l}\text { Dehalogenase specific activity* } \\
{\left[\mu \mathrm{mol} \text { substrate converted }(\mathrm{mg} \text { protein })^{-1} \mathrm{~min}^{-1}\right]}\end{array}$} \\
\hline & & & MCA & DCA & 2MCPA & 22DCPA \\
\hline \multirow[t]{2}{*}{70} & 0.04 & 19 & $\begin{array}{l}1.75 \\
0.68 \\
1.26 \\
1.16\end{array}$ & $\begin{array}{l}3.46 \\
2.03 \\
3.94 \\
2.43\end{array}$ & $\begin{array}{l}0.56 \\
0.48 \\
0.44 \\
0.49\end{array}$ & $\begin{array}{l}\text { ND } \\
0.32 \\
\text { ND } \\
0.33\end{array}$ \\
\hline & & Average & $\begin{array}{c}1.21 \\
(1.00)\end{array}$ & $\begin{array}{c}2.97 \\
(2.55)\end{array}$ & $\begin{array}{c}0.49 \\
(0.45)\end{array}$ & $\begin{array}{c}0.33 \\
(0.38)\end{array}$ \\
\hline \multirow[t]{2}{*}{390} & 0.10 & 48 & $\begin{array}{l}0.50 \\
0.05 \\
0.11 \\
0.08 \\
0.29\end{array}$ & $\begin{array}{l}0.70 \\
0.21 \\
0.40 \\
0.23 \\
0.96\end{array}$ & $\begin{array}{l}0.17 \\
0.02 \\
0.04 \\
0.02 \\
0.08\end{array}$ & $\begin{array}{l}0.10 \\
0.01 \\
0.01 \\
0.01 \\
0.03\end{array}$ \\
\hline & & Average & $\begin{array}{c}0.21 \\
(1.00)\end{array}$ & $\begin{array}{c}0.50 \\
(3.06)\end{array}$ & $\begin{array}{c}0.07 \\
(0.32)\end{array}$ & $\begin{array}{c}0.03 \\
(0.13)\end{array}$ \\
\hline \multirow[t]{2}{*}{160} & $0.15-0.18$ & $71-86$ & $\begin{array}{l}0.07 \\
0.02 \\
0.04\end{array}$ & $\begin{array}{l}0.10 \\
0.04 \\
0.10\end{array}$ & $\begin{array}{l}0.01 \\
0.01 \\
0.01\end{array}$ & $\begin{array}{l}<0.01 \\
<0.01 \\
<0.01\end{array}$ \\
\hline & & Average & $\begin{array}{c}0.04 \\
(1.00)\end{array}$ & $\begin{array}{c}0.08 \\
(1.98)\end{array}$ & $\begin{array}{c}0.01 \\
(0.30)\end{array}$ & $\begin{array}{l}<0.01 \\
(<0.08)\end{array}$ \\
\hline
\end{tabular}

ND, Not determined.

* Values in parentheses are the average of the relative dehalogenase activities standardized with respect to the MCA dehalogenation rates.

Growth on MCA in closed culture was not obtained since MCA at the initial concentrations usually used $\left(0.5 \mathrm{~g}\right.$ carbon $\left.1^{-1}\right)$ was inhibitory, and indeed growth was not obtained at 10-fold lower concentrations. This was similar to the effect of halogenated acetic acids on the growth of Pseudomonas putida PP3 previously reported (Slater et al., 1979); however, growth on these compounds can be obtained as long as continuous-flow culture systems are used to prevent the accumulation of high, toxic concentrations of halogenated alkanoic acids (Slater et al., 1979). This was achieved for Pseudomonas sp. strain E4. In closed culture with 2MCPA as the carbon source, Pseudomonas sp. strain E4 had a maximum specific growth rate $\left(\mu_{\max }\right)$ of $0.21 \mathrm{~h}^{-1}$.

A number of steady-state chemostat cultures were examined at different dilution rates to give organism growth rates which ranged from 19 to $86 \%$ of $\mu_{\max }$. The overall dehalogenase specific activities in the two series of cultures showed significant differences. With MCA as the growth-limiting substrate, the dehalogenase specific activities increased with decreasing dilution rate (Table 1) such that over the dilution rate range examined there was a 30 -fold increase in the rate with respect to MCA as the enzyme substrate, a 37-fold increase for DCA dehalogenation, a 49-fold increase for 2MCPA dehalogenation, and at least a 33-fold increase for 22DCPA dehalogenation. With 2MCPA as the growth-limiting substrate, the changes were much less marked (Table 2). The MCA dehalogenase activity was constant over the dilution rate range examined and there were slight increases in 2MCPA and 22DCPA dehalogenation rates $(2 \cdot 0-2 \cdot 5$-fold $)$ with decreasing dilution rate. Conversely, DCA dehalogenation activity increased 2 -fold with increasing dilution rate.

The substantial increases in enzyme activities for the four substrates in MCA-grown organisms could have been consistent, within the limits of experimental error, with a simple 
Table 2. Effect of dilution rate on the dehalogenase specific activities in steady-state cultures of Pseudomonas sp. strain E4 grown with 2MCPA as the growth-limiting substrate

The dehalogenase assays were repeated three or four times using different samples taken from the chemostat at a given dilution rate.

\begin{tabular}{|c|c|c|c|c|c|c|}
\hline \multirow{2}{*}{$\begin{array}{l}\text { Length of } \\
\text { steady state } \\
\text { (h) }\end{array}$} & \multirow{2}{*}{$\begin{array}{l}\text { Dilution rate } \\
\qquad\left(h^{-1}\right)\end{array}$} & \multirow[b]{2}{*}{$\begin{array}{l}\% \text { of } \\
\mu_{\max }\end{array}$} & \multicolumn{4}{|c|}{$\begin{array}{c}\text { Dehalogenase specific activity } \\
{\left[\mu \mathrm{mol} \text { substrate converted }(\mathrm{mg} \text { protein })^{-1} \min ^{-1}\right.}\end{array}$} \\
\hline & & & MCA & DCA & 2MCPA & 22DCPA \\
\hline \multirow[t]{2}{*}{80} & 0.04 & 19 & $\begin{array}{l}0.44 \\
0.41 \\
0.41 \\
0.48\end{array}$ & $\begin{array}{l}0.58 \\
0.46 \\
0.55 \\
0.49\end{array}$ & $\begin{array}{l}0.12 \\
0.17 \\
0.16 \\
0.20\end{array}$ & $\begin{array}{l}0.07 \\
0.08 \\
0.09 \\
0.08\end{array}$ \\
\hline & & Average & $\begin{array}{c}0.44 \\
(1.00)\end{array}$ & $\begin{array}{c}0.52 \\
(1.21)\end{array}$ & $\begin{array}{c}0.16 \\
(0.37)\end{array}$ & $\begin{array}{c}0.08 \\
(0.19)\end{array}$ \\
\hline \multirow[t]{2}{*}{170} & 0.09 & 43 & $\begin{array}{l}0.73 \\
0.60 \\
0.46 \\
0.41\end{array}$ & $\begin{array}{l}0.73 \\
0.73 \\
0.63 \\
0.61\end{array}$ & $\begin{array}{l}0.14 \\
0.15 \\
0.11 \\
0.09\end{array}$ & $\begin{array}{l}0.08 \\
0.08 \\
0.08 \\
0.08\end{array}$ \\
\hline & & Average & $\begin{array}{c}0.55 \\
(1.00)\end{array}$ & $\begin{array}{c}0.68 \\
(1.27)\end{array}$ & $\begin{array}{c}0.12 \\
(0.23)\end{array}$ & $\begin{array}{c}0.08 \\
(0.15)\end{array}$ \\
\hline \multirow[t]{2}{*}{50} & 0.18 & 86 & $\begin{array}{l}0.27 \\
0.73 \\
0.47\end{array}$ & $\begin{array}{l}0.63 \\
1.74 \\
1.13\end{array}$ & $\begin{array}{c}0.04 \\
\text { ND } \\
0.08\end{array}$ & $\begin{array}{l}0.02 \\
0.07 \\
0.03\end{array}$ \\
\hline & & Average & $\begin{array}{c}0.49 \\
(1.00)\end{array}$ & $\begin{array}{c}1.17 \\
(2.37)\end{array}$ & $\begin{array}{c}0.06 \\
(0.16)\end{array}$ & $\begin{array}{c}0.04 \\
(0.08)\end{array}$ \\
\hline
\end{tabular}

\footnotetext{
ND, Not determined.

* Values in parentheses are the average of the relative dehalogenase activities standardized with respect to the MCA dehalogenation rates.
}

increase in the proportion of a single enzyme, which would have resulted in a constant relative dehalogenase activity ratio at all steady states. This was not observed (Table 1): both the relative activities of $2 \mathrm{MCPA}$ and 22DCPA with respect to the MCA dehalogenation rate increased with decreasing dilution rate and there was a variable response for the ratio of DCA to MCA (Table 1). Similarly, the variations in the relative dehalogenase activities for organisms grown on 2MCPA were not consistent with changes in the cellular content of a single dehalogenase (Table 2). As expected, the ratio of activities for the four substrates varied in a similar fashion to the changes in dehalogenase specific activities.

Initially, 2MCPA- and MCA-limited chemostats were operated at dilution rates $(D)$ of about $0.1 \mathrm{~h}^{-1}$, representing approximately $45 \%$ of $\mu_{\max }$. Under these conditions it was apparent that the patterns of dehalogenase activities expressed were different from those observed in the original closed cultures. Moreover, there were differences when the organism was grown under different limitations (Figs 1 and 2).

With MCA as the carbon source, only dehalogenase I was demonstrated at $D=0 \cdot 1 \mathrm{~h}^{-1}$ (Fig. 1), whereas with 2MCPA as the carbon source, dehalogenases II and III were also detected with the major enzyme, dehalogenase I. Several different steady-state cultures at $D=0.1 \mathrm{~h}^{-1}$ were examined in the case of 2MCPA-limited growth and the expression of dehalogenases II and III was variable: usually both enzymes were detected but occasionally only one of them was seen on the polyacrylamide gels. However, it must be stressed that the activities of dehalogenases II and III were very low compared with dehalogenase I and close to the minimum level of detection by the gel visualization technique. It cannot be excluded that both were always present but not observed.

As might have been expected from the overall differences in the changes of dehalogenase specific activities and relative dehalogenase activities, changes in the dilution rates of the two 


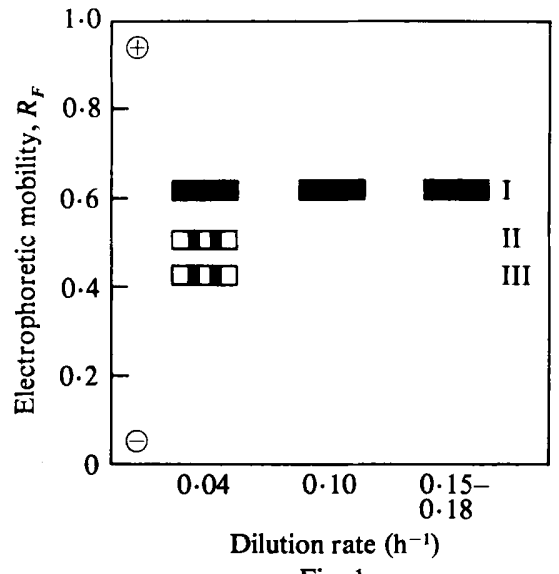

Fig. 1

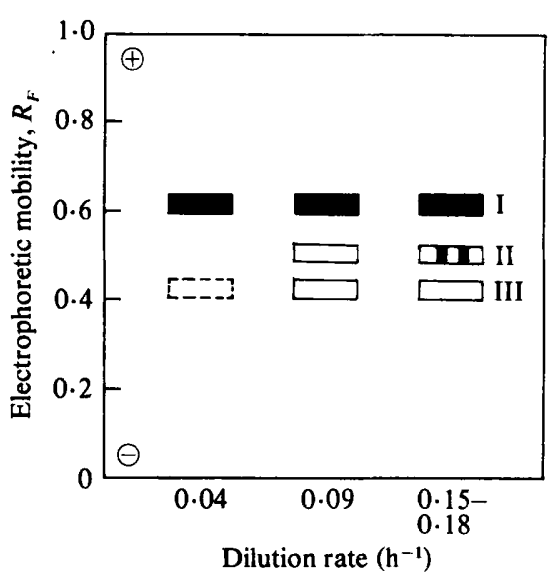

Fig. 2

Figs 1 and 2. Patterns of dehalogenases I, II and III activities towards a mixture of MCA and DCA for Pseudomonas sp. strain E4 grown at different dilution rates on MCA (Fig. 1) or 2MCPA (Fig. 2) as the growth-limiting substrate. The bars represent semi-quantitative assessments of enzyme activity towards MCA and DCA ranging from slight/occasional to great in the sequence [--

cultures resulted in different enzyme complements depending on the nature of the growth-limiting substrate.

When MCA was the growth-limiting substrate, increasing the dilution rate to $86 \%$ of $\mu_{\max }$ $\left(D=0.18 \mathrm{~h}^{-1}\right)$ resulted in no change, with only dehalogenase I apparently present (Fig. 1). However, decreasing the dilution rate to $19 \%$ of $\mu_{\max }\left(D=0.04 \mathrm{~h}^{-1}\right)$ resulted in a gradual change of the dehalogenase profile to include dehalogenases II and III as well as dehalogenase I (Fig. 1). Although the polyacrylamide gels showed that most of the MCA dehalogenase activity was associated with dehalogenase I, the second and third enzymes showed substantially more activity than when these enzymes were expressed in Pseudomonas sp. strain E4 grown at $D=0.09 \mathrm{~h}^{-1}$ under 2MCPA limitation.

The results were different when the organism was grown on 2MCPA as the sole carbon and energy source. At a low dilution rate $\left(D=0.04 \mathrm{~h}^{-1}\right)$ only dehalogenase I was detected although occasionally dehalogenase III appeared to be active on polyacrylamide gels (Fig. 2). At the highest dilution rate examined $\left(D=0.18 \mathrm{~h}^{-1}\right)$ low levels of dehalogenases II and III were detected with the activity of dehalogenase II always significantly greater than dehalogenase III but less than dehalogenase I (Fig. 2).

\section{DISCUSSION}

The results demonstrate the problems associated with the analysis of physiological and biochemical parameters solely on the basis of results obtained with organisms grown in closed culture. Two major observations may be made.

Firstly, growth under substrate-limited conditions resulted in the synthesis of a third dehalogenase which had not been suspected from the analysis of Pseudomonas sp. strain E4 grown on 2MCPA in closed culture (Hardman \& Slater, 1981). The electrophoretic mobility of the novel strain E4 dehalogenase corresponded to one of the dehalogenases found in other strains of Gram-negative bacteria isolated from the same soil samples (Hardman \& Slater, 1981). The dehalogenase III found in these other strains was expressed in organisms grown in closed culture, demonstrating that the regulation of synthesis and expression has been 
modified in Pseudomonas sp. strain E4. Thus, in addition to problems associated with the evolutionary relationships between the various dehalogenases found in soil bacteria, this extra variation will enable aspects of the evolution of regulatory control to be examined.

Secondly, the data obtained from the chemostats demonstrated variations in the control of enzyme synthesis which were not anticipated from the closed culture studies. At equivalent growth rates the enzyme activity expressed was dependent on the nature of the growth-limiting substrate. At the lowest dilution rate examined the MCA and 2MCPA dehalogenation rates were approximately 3 -fold greater when MCA was the growth-limiting substrate compared with 2MCPA (Table 1). At the highest dilution rate, however, the rate of MCA dehalogenation was 12-fold lower and the rate of 2MCPA dehalogenation was 6 -fold lower for organisms grown with MCA-limitation compared with those grown with 2MCPA-limitation. Previous studies with other systems have demonstrated considerable variations in enzyme activity responses as a function of the nature of the growth-limiting substrate and dilution rate (Clarke \& Lilly, 1969; Dean, 1972; Bolton \& Dean, 1972; Almengor-Hecht \& Bull, 1978; Bull \& Brown, 1979). The dehalogenase systems in Pseudomonas putida strain PP3 and Pseudomonas sp. strain E4 have now exemplified three standard responses. Pseudomonas putida PP3 grown on 2MCPA has been shown previously to exhibit a peak of activity at a given dilution rate, a response normally considered to be characteristic of catabolic enzymes (Slater et al., 1979; Weightman \& Slater, 1980). Pseudomonas sp. strain E4 showed a continuous increase in enzyme specific activity with decreasing dilution rate when MCA was the substrate, although it cannot be excluded that at lower dilution rates than $D=0.04 \mathrm{~h}^{-1}$ a decrease might have been observed thereby providing a peak of activity at a low dilution rate. Finally, with 2MCPA as the substrate the response was varied and depended on the substrate examined (Table 2). In part, the variations in response, particularly for the organisms grown on 2MCPA as the limiting substrate, must reflect the variations in the enzyme complement as a function of dilution rate. Thus, the overall rate of dehalogenation measured in cell-free extract will depend not only on the amounts of each dehalogenase expressed but also on their individual kinetic properties, particularly $V_{\max }$ and $K_{\mathrm{m}}$. These properties of the various dehalogenases remain to be determined but their interaction as a function of dilution rate is likely to be similar to that observed for two anaplerotic tricarboxylic acid cycle enzymes, pyruvate carboxylase and phosphoenolpyruvate carboxylase, demonstrated in glucose-limited cultures of Aspergillus nidulans as a function of growth rate (Bushell \& Bull, 1981).

The response of Pseudomonas sp. strain E4 to growth on MCA appears to be more readily explained than its response to growth on 2MCPA. It has previously been shown that dehalogenase I more readily dechlorinates chloroacetates than chloropropionates (Hardman \& Slater, 1981), and the minimum activity exhibited at high growth rates is comparable to the minimum activities observed for P. putida PP3 (Slater et al., 1979) and is sufficient to account for growth. As the dilution rate decreases the concentration of unmetabolized MCA also decreases which results in greater enzyme synthesis and the derepression of other enzymes, processes which may increase the rate at which slowly growing Pseudomonas $\mathrm{sp}$. strain E4 can sequester limiting amounts of MCA present at low concentrations in its environment. Such an explanation cannot be advanced for organisms grown on 2MCPA since, in the case of dehalogenase II, the reverse pattern is observed, with more of this enzyme synthesized at higher growth rates (Fig. 2). This is particularly puzzling since it has been previously demonstrated that dehalogenase II carries little or no activity towards 2MCPA (Hardman \& Slater, 1981). It seems, therefore, that there exist complex interactions between the regulatory mechanisms which cannot be interpreted simply in terms of the normal, expected response and the capability of the organism.

D.J.H. thanks the Natural Environment Research Council for a Research Studentship. J.H.S. acknowledges the support for parts of this work from The Royal Society. We thank Andrea H. Filipiuk for excellent technical assistance. 


\section{REFERENCES}

Almengor-Hecht, M. L. \& Bull, A. T. (1978). Continuous-flow enrichment of a strain of Erwinia carotovora having specificity for highly methylated pectin. Archives of Microbiology 119, 163-166.

Bolton, P. G. \& DeAN, A. C. R. (1972). Phosphatase synthesis in Klebsiella (Aerobacter) aerogenes growing in continuous culture. Biochemical Journal 127, 87-96.

Bull, A. T. \& Brown, C. M. (1979). Continuous culture applications to microbial biochemistry. In International Review of Biochemistry, vol. 21, Microbial Biochemistry, pp. 177-226. Edited by J. R. Quayle. Baltimore: University Park Press.

Bull, A. T., Senior, E. \& Slater, J. H. (1976). Concerning the evolution of metabolic capabilities in bacteria: Dalapon (2,2-dichloropropionic acid) metabolism by Pseudomonas putida. Proceedings of the Society for General Microbiology 4, 39.

Bushell, M. E. \& Bull, A. T. (1981). Anaplerotic metabolism of Aspergillus nidulans and its effect on biomass synthesis in carbon limited chemostats. Archives of Microbiology 128, 282-287.

Clarke, P. H. \& Lilly, M. D. (1969). The regulation of enzyme synthesis during growth. Symposia of the Society for General Microbiology 19, 113-159.

DEAN, A. C. R. (1972). Influence of environment on the control of enzyme synthesis. Journal of Applied Chemistry and Biotechnology 22, 245-259.

Goldman, P., Milne, G. W. A. \& Keister, D. B. (1968). Carbon-halogen bond cleavage. III. Studies on bacterial halidohydrolases. Journal of Biological Chemistry 243, 428-434.

Gornall, A. G., Bardawill, C. J. \& David, M. M. (1949). Determination of serum proteins by means of the biuret reaction. Journal of Biological Chemistry 177, 751-766.

HaRdman, D. J. \& Slater, J. H. (1981). Dehalogenases in soil bacteria. Journal of General Microbiology 123, 117-128.

JENSEN, H. L. (1960). Decomposition of chloroacetates and chloropropionates by bacteria. Acta agriculturae scandinavica 10, 83-103.

LitTle, M. \& Williams, P. A. (1971). A bacterial halidohydrolase: its purification by specific amino acid reagents. European Journal of Biochemistry 21, 99-109.

Slater, J. H., Lovatt, D., Weightman, A. J., SENIOR, E. \& BULL, A. T. (1979). The growth of Pseudomonas putida on chlorinated aliphatic acids and its dehalogenase activity. Journal of General Microbiology 114, 125-136.

Weightman, A. J. \& Slater, J. H. (1980). Selection of Pseudomonas putida strains with elevated dehalogenase activities by continuous culture growth on chlorinated alkanoic acids. Journal of General Microbiology 121, 187-193. 